Int. J. Odontostomat.,

15(3):626-633, 2021.

\title{
¿Los Quistes Periradiculares Dependen de la Infección Endodóntica?
}

\author{
¿Radicular Cysts Depend on Endodontic Infection?
}

\author{
Karen Brisson Suárez'; Alessandra Baasch'; Sabrina de Castro Brasil'; \\ Juan D. Saavedra F.'; Luciana Armada ${ }^{3}$ \& Flavio R. F. Alves ${ }^{1}$
}

\begin{abstract}
BRISSON, S. K.; BAASCH, A.; DE CASTRO BRASIL, S.; SAAVEDRA, F. J. D.; ARMADA, L. \& ALVES, F. R. F. ¿LOS quistes periradiculares dependen de la infección endodóntica? Int. J. Odontostomat, 15(3):626-633, 2021.

RESUMEN: Los quistes periradiculares, tanto los de bolsillo como los verdaderos, son de origen inflamatorio; sin embargo, en la literatura ha existido una gran controversia asociada, en primer lugar, a la dependencia de la infección contenida dentro del sistema de conductos radiculares y, en segundo lugar, al tipo de tratamiento endodóntico llevado a cabo en este tipo de lesiones. Con el fin de dilucidar esta controversia se realizará una revisión a la literatura sobre quistes periradiculares donde se explicará cuál es la técnica más adecuada en el diagnóstico de quistes verdaderos y de bolsillo. Igualmente, se explicará la teoría de autosustentabilidad, así como el tratamiento endodóntico de grandes lesiones periradiculares asociadas a dichos quistes. Ahora bien, en la actualidad se ha demostrado que ambos quistes están asociados a infecciones contenidas en el sistema de conductos radiculares y son diferentes solamente en su morfología. Así mismo, se ha recomendado el tratamiento de conducto convencional en dientes con grandes lesiones asociadas a quistes.
\end{abstract}

PALABRAS CLAVE: periodontitis apical, quiste de bolsillo, quistes verdadero.

\section{INTRODUCCIÓN}

La periodontitis apical es el término utilizado para describir un proceso inflamatorio en la región perirradicular que ocurre en respuesta a la interacción de microorganismos o de sus irritantes dentro del sistema de conductos con el sistema inmune del hospedero. Dependiendo del tipo de agresión la respuesta de este puede ser aguda o crónica. Las lesiones crónicas se caracterizan por ser asintomáticas y por presentar una agresión de baja intensidad; así mismo, puede ser controlada por los mecanismos de defensa del hospedero, lo cual viene dado por la falta de suministro sanguíneo por parte de la pulpa dental. Por lo tanto, las células del hospedero no pueden llegar a la fuente de irritación y el cuerpo no puede eliminar la infección dentro del sistema de conductos, generándose así una inflamación crónica en la región periapical (Abbott, 2004; Siqueira-jr \& Rôças, 2007).

Las lesiones crónicas periradiculares por lo general, contienen células epiteliales y se cree que pro- vienen de los restos epiteliales de Malassez (Nair et al.,1996; Nair, 1997; Ricucci et al., 2006). La estructura histopatológica de los quistes periradiculares tienen una importancia particular y pudo ser observado en el estudio de Simon (1980). Allí expuso dos tipos de quistes; aquellos que estaban completamente recubiertos de epitelio los denominó quistes verdaderos y aquellos donde el tejido epitelial estaba en contacto con el ápice del conducto radicular los denominó quiste de bahía.

Sin embargo, el quiste verdadero, a diferencia del quiste de bolsillo, es una entidad que no está en contacto con el ápice radicular, por lo tanto, Nair et al. (1993) explican que los mismos son autosustentables por la dinámica del tejido en la lesión y que no dependen de la ausencia o presencia de irritantes dentro del sistema de conductos. Por esta razón, la mayoría de los clínicos, al observar una lesión de gran tamaño, la asocian con quistes basándose en esta teoría que ha

\footnotetext{
${ }^{1}$ Programa de Postgrado en Odontología. Universidad de Rio Grande. Unigranrio. Rio de Janeiro, Rj. Brasil.

${ }^{2}$ Práctica Privada en Endodoncia y Microcirugía Endodóntica, Caracas, Venezuela.

${ }^{3}$ Departamento de Endodoncia, Facultad de Odontologia, Universidad Estácio de Sá, Rio de Janeiro, RJ, Brasil.
} 
sido mantenida por años. Además, tienden a elegir la cirugía perirradicular como primera opción en el tratamiento de este tipo de lesión, ya que se supone que con el tratamiento de conducto convencional no se lograría la curación en la región apical. No obstante, Ricucci et al. (2020) exponen que ambos tipos de quistes aparentan ser diferentes solo en la morfología y, por otra parte, no abalan la teoría que presenta al quiste verdadero como una entidad autosustentable, puesto que, al igual que el quiste de bolsillo, es mantenido por la infección del sistema de conductos radiculares y que al eliminarse los irritantes por medio de la terapia endodóntica convencional estos tienden a curar.

Por consiguiente, al existir esta controversia, el objetivo de esta revisión está enfocado en discutir si los quistes son o no dependientes de la infección endodóntica y cuál es el tratamiento ideal para este tipo de lesiones periradiculares.

\section{REVISIÓN}

Diferencia entre los quistes periradiculares. El término quiste deriva del griego Kist que significa saco o vejiga. En los maxilares se han evidenciado, varios tipos quistes, sin embargo, los que están asociados a pulpas necróticas infectadas y son de origen inflamatorio, se han denominado quistes periradiculares (Nair, 2003). Por lo general estos, no tienen predilección por el género, sin embargo, se ha demostrado que tienen cierta preferencia por el sexo femenino; en relación a la edad, se ha observado en mayor número en pacientes adultos al igual que los granulomas (Alcantara et al., 2013). Según Lin et al. (2009) lo quistes periradiculares se derivan de los granulomas y podría considerarse como una forma de hiperplasia patológica (inflamatoria) de restos de celulares epiteliales de lesiones periradiculares.

Este proceso inflamatorio se caracteriza en primer lugar por la proliferación de los restos celulares epiteliales de Malassez, que se encuentran en el ligamento periodontal (Bernardi et al., 2015). Sugieren que estos restos epiteliales en dientes sanos, son estables y tienen un potencial regenerativo que tienden a experimentar división celular y proliferar por el resultado de la interacción de mediadores químicos de la inflamación como las prostaglandinas (PGE2), citosinas proinflamatorias tales como, Interleucinas (IL)-1, (IL)-6, y por último se encuentran los factores de crecimiento liberados por el hospedero durante el proceso inflamatorio en los tejidos periradiculares, entre estos tenemos a el factor de crecimiento epidérmico (EGF), el factor de crecimiento queratinositico (KGF), factor de crecimiento similar a la insulina que son liberados por fibroblastos estromales, por otra parte se encuentran el factor de necrosis tumoral alfa (FNTa) liberados por los eosinófilos, macrófagos y linfocitos (Lin et al.,2007). Durante este proceso, también ocurre una resorción ósea por parte de los osteoclastos, activados por las citosinas proinflamatorias que se activan creando una cavidad ósea (Nair, 1997; Siqueira-jr \& Rôças, 2007). Esta cavidad está compuesta por el lumen que es la parte central y por tejido epitelial que se encuentra recubriendo la cavidad (Bhaskar, 1966; Nair et al., 1996; Ricucci et al., 2006). En un estudio de Lin et al. (2009) sugieren que el lumen de los quistes periradiculares está compuesto por tejido conjuntivo fibroso, exudado inflamatorio, colonias bacterianas, fluido cristalino, cristales de colesterol y, por último, células inflamatorias, entre ellas macrófagos que por lo general están activos y células gigantes multinucleadas. Estos dos tipos de células inflamatorias se han observado alrededor de los cristales de colesterol y tienen la finalidad de realizar el proceso de fagocitosis sobre dichos cristales (Fig. 1)

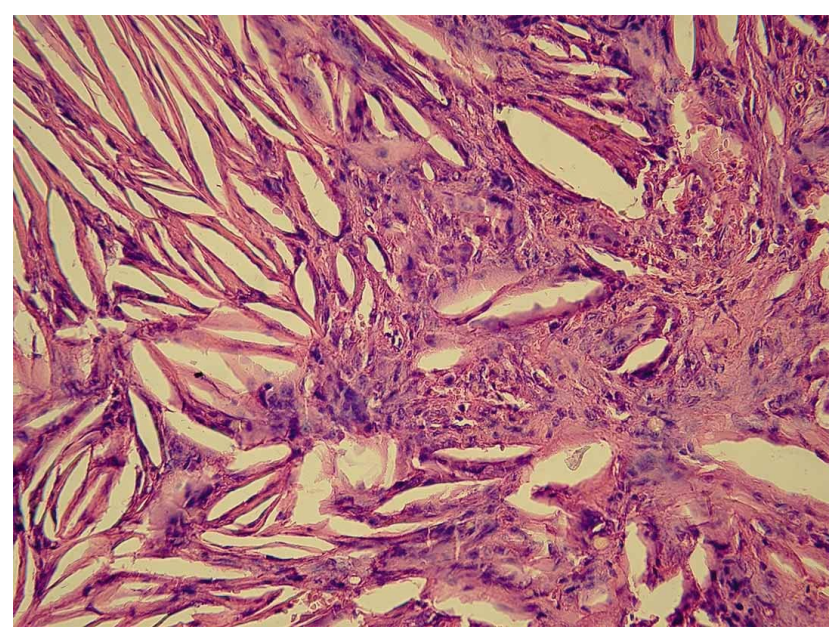

Fig. 1. Fotomicrografía de quiste periradicular, se evidencia la presencia de cristales de colesterol H\&E. 200

Otro de los componentes del quiste es el epitelio que recubre esta cavidad, en la mayoría de los casos es epitelio escamoso estratificado, sin embargo, algunos estudios han demostrado que, en el maxilar superior, la mayoría de los quistes están recubiertos por epitelio columnar ciliado. Suponen que es por la cercanía que tienen los ápices al seno maxilar (Ricucci et al., 2006; Ricucci et al.,2020), (Fig. 2). 

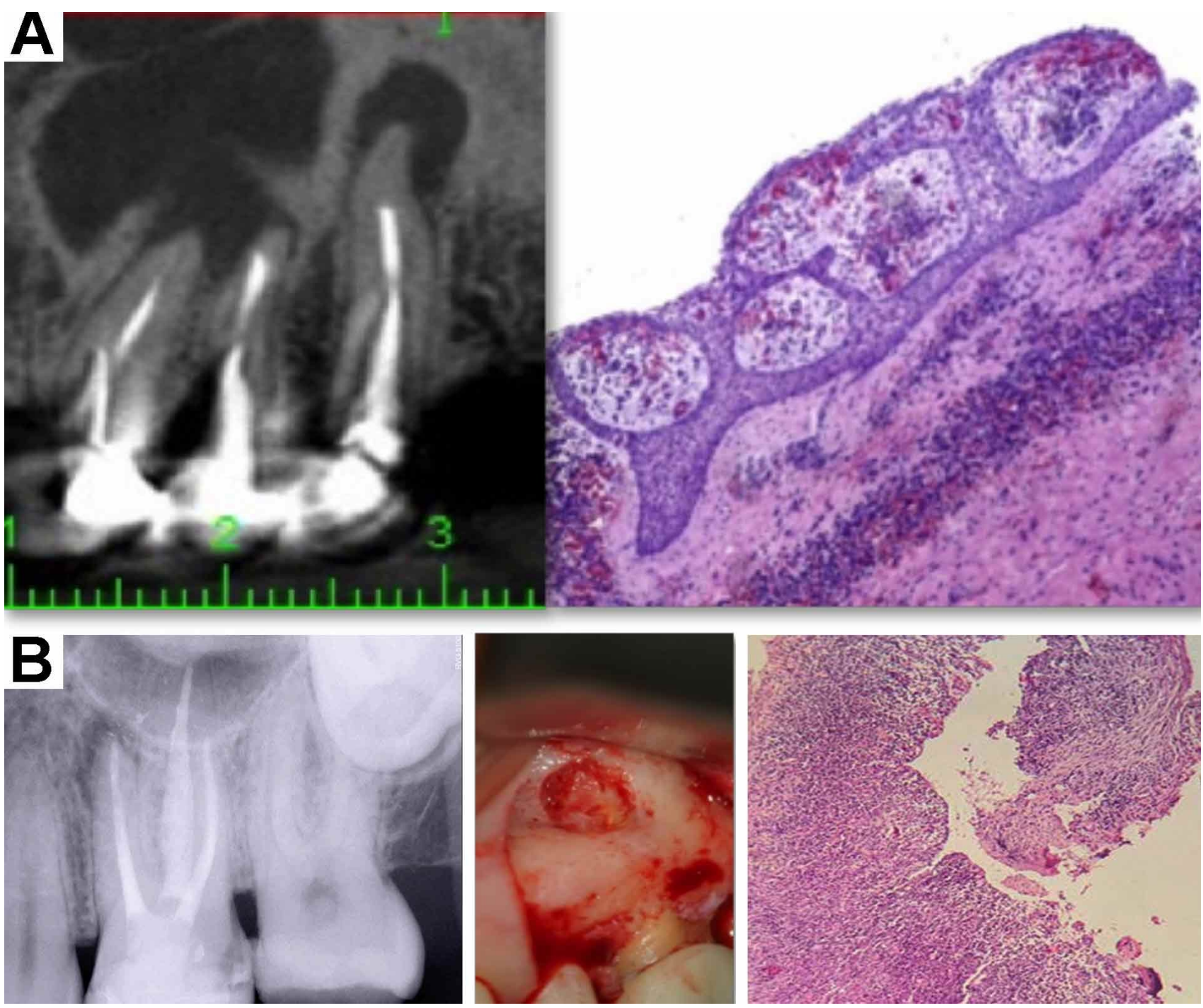

Fig. 2. Casos de quistes periradiculare (A) Zona anterosuperior izquierda. Corte coronal de la zona 2.2- 2.4, Fotomicrografía donde se evidencia quiste periradicular H\&E 100x. (B) Caso de quiste periradicular en primer molar superior derecho. Radiografía periapical se evidencia imagen radiolúcida periradicular en la raíz mesiovestibular, fotografía clínica de la cirugía endodóntica presencia de la lesión y fotomicrografía evidencia quiste periradicular H\&E 10X.

El epitelio del quiste se puede dividir en células suprabasales y células basales. Las células suprabasales son células diferenciadas, mientras que las células basales son células madres capaces de realizar una división celular para reemplazar a las células suprabasales descamadas por la pérdida de suministro sanguíneo o nutricional. Las células basales están ancladas a la lámina basal y separada del tejido conectivo fibroso por una capa de la membrana basal. Tanto la cápsula de tejido conectivo fibroso como el epitelio de revestimiento suelen estar infiltrados por grados variables de células inflamatorias agudas y crónicas (Lin et al., 2009).
Simon, distinguió y especificó las diferencias del tejido epitelial en los quistes periradiculares. A uno de estos quistes lo denominó "Bahía" y al otro solo "Quiste". El de Bahía se caracterizó porque la cavidad que contenía la lesión inflamatoria estaba recubierta por epitelio, pero interrumpida por el ápice radicular, es decir estaba en contacto con el sistema de conductos radiculares. Mientras que, en los otros, el epitelio solo recubría la cavidad de la lesión inflamatoria, sin estar en contacto con el foramen y el sistema de conductos radicular.

Posteriormente, Nair et al. (1996) clasificaron a 
los quistes periradiculares como quiste de "Bolsillo" y "Verdadero". El quiste de "Bahía", propuesto por Simon, lo denominaron como quiste de "Bolsillo" y lo definió como una cavidad revestida de epitelio en forma de saco, que se encuentra en contacto con el conducto radicular; sin embargo, prefirieron denominarlo de esta forma porque el epitelio entra en contacto con la superficie de la raíz y parece sellar el ápice del conducto radicular infectado. Mientras que el quiste verdadero no está en contacto con el ápice del conducto radicular y el lumen está revestido por tejido epitelial.

En relación a la patogénesis en los dos tipos de quistes la Primera Fase está comprendida por la proliferación del tejido epitelial. Por una parte, en los quistes de bolsillo, esta proliferación puede formar un collar de tejido epitelial alrededor de la superficie externa del ápice, de igual forma proponen que la presencia de microorganismos contenida dentro de conducto radicular atrae a los neutrófilos, por medio del proceso de quimiotaxis, al lumen del quiste, formando una especie de saco. Por otra parte, se encuentran los quistes verdaderos que en su Segunda Fase de formación lo sustentan dos teorías: (I) La Teoría de deficiencia nutricional, propone que las células epiteliales son removidas de su fuente de nutrición degenerándose y posteriormente los neutrófilos se fusionan con el fluido tisular para formar la cavidad del quiste. (II) "La teoría del absceso" postula que las células epiteliales tienen la naturaleza innata de recubrir el tejido conectivo y, una vez que proliferan por medio de la necrosis y lisis de este tejido, forman una cavidad de absceso. En la Tercera Fase de los quistes verdaderos, estos pueden crecer por el resultado de la presión osmótica del fluido del quiste (Nair, 1998; Nair, 2003). Sin embargo, Lin et al. (2007) expresan que esta última fase no tiene fundamento, ya que una vez instaurada la lesión perirradicular se activa el proceso inflamatorio que aparte de estimular la proliferación epitelial causa resorción ósea. También plantean la hipótesis que los quistes apicales inflamatorios probablemente se formen por la fusión de hebras epiteliales que proliferan en varias direcciones para formar una masa esférica tridimensional. Dentro de esta masa, se encuentra tejido conectivo fibroso con diversas células inflamatorias que se degeneran gradualmente por la pérdida de suministro de sangre y posteriormente se formará una cavidad quística.

Técnicas utilizadas en la diferenciación de quistes verdaderos y bolsillo. En dos estudios que se caracterizaron por determinar la incidencia y los tipos de lesiones periradiculares se tomaron en cuenta 2308 dientes y 800 dientes, Bhaskar y Lalonde \& Luebke (1968), respectivamente. En ambos las muestras fueron obtenidas de la extracción de los dientes y de la remoción completa de toda la lesión de los ápices dentales. Explican que el criterio tomado en cuenta para el diagnóstico entre quistes y granulomas fue que los quistes radiculares estuvieran completamente recubiertos de epitelio. Bhaskar encontró que 969 muestras, es decir, el $42 \%$ corresponden a quistes.

Por otra parte, Lalonde \& Luebke encontraron que 350 casos el $43,8 \%$ también fueron quistes. Estos estudios no tuvieron un criterio estricto de selección de muestra. Por ejemplo, en ninguno de los dos estudios especificaron la cantidad de las muestras tomadas por endodoncistas, odontólogos generales o cirujanos bucales, solo refieren que la mayoría fue tomada por endodoncistas según Bhaskar y por cirujanos según Lalonde \& Luebke. Otro criterio que no se tomó en cuenta, fue la selección de los casos a evaluar, ya que tomaron solo dientes extraídos que presentaban lesiones perirradiculares sin tener en cuenta si los dientes estaban tratados 0 no endodónticamente (Bhaskar).

Por otra parte, Nair et al. (1996) y Simon explican que, al remover completamente la lesión del ápice radicular, por medio del curetaje, como fue llevado a cabo en los estudios de Bhaskar y Lalonde \& Luebke y luego someterlo bajo observación en el microscopio, no se puede determinar claramente cuáles lesiones son quistes o granulomas, puesto que algunos granulomas contienen tejido epitelial y están adheridos al ápice del diente. Esto podría explicar la alta incidencia en quistes y la variación en todos los estudios donde se usa biopsias con curetaje.

Por lo mencionado anteriormente diversos estudios (Nair et al., 1996; Ricucci et al., 2006; Ricucci \& Siqueira-jr, 2010; Ricucci et al., 2020; Simon) han aplicado el método de secciones seriadas que consiste en un corte de un lado al otro de la lesión perirradicular adherida al ápice dental con la finalidad de observar cuál es relación de la lesión perirradicular con el foramen apical. Simon describe los tipos de lesiones periradiculares y cómo es el epitelio en cada una de ellas. Sin embargo, expone que una de las limitaciones de este estudio es la poca cantidad de muestra $(n=35)$, ya que en el procedimiento algunas de estas, correspondientes a quiste de bahía, se desalojaron del ápice radicular y no fueron tomadas en cuenta para el estudio. 
Por otra parte, Nair et al. (1996) también realizó un estudio para observar histológicamente si los quistes periradiculares se clasificaban en dos categorías como fue establecido en el estudio anterior, hace la observación de que en este estudio las microfotografías tomadas revelan que tanto en los ápices radiculares como en el epitelio que recubre el quiste había un daño severo y esto podría haber influenciado críticamente en la clasificación de los quistes. Por esta razón, en su estudio, menciona que los dientes utilizados fueron cuidadosamente extraídos, por otra parte, el número de la muestra fue mayor, ya que tomaron 256 lesiones que previamente por medio de radiografías, fueron diagnosticados con periodontitis apical de dientes no vitales. Al evaluar la relación del epitelio con el ápice radicular, observaron que el $52 \%$ de todas las muestras presentaron tejido epitelial y que el $15 \%$ fueron diagnosticadas como quiste, $61 \%$ verdaderos y $39 \%$ bahía-bolsillo. Por lo tanto, cuando se hace un estudio con buena selección de los casos y un buen método de obtención de la muestra, se puede conseguir un diagnóstico histopatológico más acertado sobre los quistes verdaderos o de bahía o bolsillo.

Como ocurrió en el estudio de Ricucci et al. (2006) que también evaluó la presencia de epitelio adherido a las raíces dentales. La muestra fue menor que en el estudio anterior, en este se tomaron solo 50 lesiones periradiculares adheridas a los ápices de dientes que no tenían tratamiento de conducto por medio de la extracción. Sin embargo, estas muestras fueron tomadas de una única consulta dental y fueron excluidos aquellos dientes que presentaban lesiones endoperiodontales, así como fracturas longitudinales o fisuras. De estas muestras, 16 fueron quistes radiculares; 7 fueron quistes verdaderos y 8 de bolsiIlo. Explica que es probable que este estudio presente un sesgo, ya que primero los dientes no fueron tratados endodónticamente y por ende no pudo evaluar la duración de la periodontitis apical y, por último, los dientes en su mayoría no eran restaurables. No obstante, tanto el protocolo para la obtención de la muestra y el diagnostico histopatológico fue muy estricto.

Buscando ser más estrictos en el estudio de los quistes, Ricucci et al. (2020) evaluaron la prevalencia, manifestaciones clínicas, radiográficas, histopatología e histobacteriología de 95 muestras obtenidas cuidadosamente por extracción o cirugía endodóntica de dientes con lesiones apicales adheridas a ápices dentales de dientes tratados 0 no tratados endodónticamente. En este estudio también llevaron a cabo las secciones seriadas en cada muestra, con la finalidad de ver cuál es la relación entre el ápice y los quistes perirradiculares. Observaron que no hay ninguna diferencia en las variables evaluadas y que estos tipos de quistes solo son diferentes en la morfología y en la relación de la cavidad del mismo con el conducto radicular.

Teoría de autosustentabilidad de los quistes perirradiculares. Esta teoría expuesta por Nair et al. (1993) explica como es el mecanismo de autosustentabilidad de los quistes verdaderos. En este estudio, llevado a cabo con un solo paciente, realizaron el tratamiento de conducto convencional y por medio de cultivo en el momento de obturar no encontraron microorganismos antes de la obturación. Después de 44 meses de seguimiento, persistió la lesión perirradicular y la cirugía perirradicular fue planificada. Una vez obtenida la muestra, la observación fue llevada a cabo mediante el microscopio electrónico de barrido, se observó tanto el ápice radicular por medio del corte de secciones seriadas y también la lesión adherida al ápice radicular. No observaron microorganismos en la porción apical del conducto ni en la lesión. Tampoco observaron la presencia de polimorfonucleares ni microabscesos alrededor del ápice radicular. El hallazgo principal de este estudio fue la presencia de cristales de colesterol dentro de la lesión y alrededor de estas numerosas células gigantes multinucleadas, sugieren que la acumulación de estos cristales y la condición quística propia de la lesión puede afectar negativamente el proceso de curación de la lesión después de realizar la terapia endodóntica.

Se debe resaltar que solo un diente fue evaluado en este estudio, mientras que en el estudio de Ricucci \& Siqueira-jr (2010) evaluaron 106 casos de dientes con o sin tratamiento endodóntico. En los resultados solo un diente asintomático tratado endodónticamente que presentaba lesión perirradicular, no tuvo presencia de microorganismos; sugieren que puede ser una reacción a cuerpo extraño. Otro de los criterios tomados en cuenta en la detección de microorganismos antes de culminar el tratamiento de conducto fue el cultivo y, luego de realizar la cirugía perirradicular, fue bajo la observación del microscopio electrónico de barrido. En relación al cultivo Siqueira-jr \& Rôças (2005) explican que este tipo de método de detección bacteriana tiene varias desventajas, entre estas se encuentra la dificultad de identificar especies bacterianas y la imposibilidad de cultivar un gran número de especies. Por otra parte, Nair et al. (1990) explican que la observación por medio 
del microscopio electrónico no tiene gran utilidad para detectar las bacterias en infecciones persistentes de tratamientos, porque con el microscopio solo se puede examinar un área extremadamente limitada de la muestra, por lo tanto, las bacterias pueden pasar desapercibidas. Se puede concluir que ambos métodos tienen baja sensibilidad en la detección de bacterias.

Por lo antes mencionado, varios estudios han utilizado la histobacteriología como método de detección de microorganismos (Ricucciet al., 2006; Ricucci \& Siqueira-jr, 2010; Ricucci et al., 2020); este método permite una mejor distinción de los contaminantes bacterianos cuando se comparan con otros, dado que este provee información sobre la ubicación espacial de las bacterias en la lesión y su asociación con la inflamación (Ricucci et al., 2020). En esta técnica se utiliza la tinción de Brown-Brenn, que es una modificación de la técnica de tinción de Gram y se caracteriza por ser más sensibles en la detección de bacterias que otras técnicas (Ricucci et al., 2006).

Otro de los estudios que evaluaron por medio de la histobacteriología la asociación de biopelículas en dientes tratados o no endodónticamente con el tipo de lesión perirradicular fue Ricucci \& Siqueira-jr (2010), uno de sus objetivos era evaluar la asociación de biopelículas en dientes tratados endodónticamente o no con el tipo de lesión perirradicular y encontraron que estas biopelículas interradiculares estuvieron mayormente presentes en conductos con lesiones epitelializadas entre ellos abscesos, granulomas y quistes. En cuanto al tipo, las biopelículas interradiculares fueron significativamente mayor en los casos diagnosticados como quistes (95\%). Esto puede ser posible ya que los quistes son el resultado de la proliferación de algunos granulomas, por lo consiguiente es razonable asumir que lesiones apicales de larga data tengan una gran probabilidad de convertirse en quistes.

El primer estudio en comparar mediante la histobacteriología, el componente bacteriano de los quistes verdaderos y de bolsillo fue Ricucci et al. (2020). Los autores observaron que el patrón de infección fue el mismo para ambos tipos de quistes y explican que en todos los casos hubo presencia de bacterias independientemente de si el diente estaba tratado endodónticamente o no, o si el quiste era verdadero o de bolsillo. Bacterias extrarradiculares también fueron encontradas, en mayor cantidad en el lumen de los quistes y en menor cantidad en forma de biopelículas adheridas a la superficie externa del diente.
Tratamiento de lesiones de gran tamaño asociadas a quistes perirradiculares. Como se ha explicado anteriormente, a lo largo de la historia se ha mantenido la teoría que los quistes bolsillo están en contacto con la fuente de irritación proveniente del conducto radicular y que al realizar el tratamiento de conducto los dientes con este tipo de quistes logran curar, mientras que los quistes verdaderos no dependen de una fuente de irritación, son "autosustentables" y necesitan ser removidos por medio de la cirugía para alcanzar la curación (Nair et al.,1993; Nair et al.,1996; Simon).

Es importante resaltar que estas suposiciones no pueden ser identificadas en la planificación del tratamiento, ya que el diagnóstico de quistes radiculares no se puede establecerse a través de exámenes clínicos, radiográficos (Bhaskar; Lalonde \& Luebke; Ricucci et al., 2020) ni con tomografía computarizada (Rosenberg et al., 2010), solo con el diagnóstico histopatológico (Bhaskar; Lalonde \& Luebke;Ricucci et al., 2020; Rosenberg et al.). No obstante Morse et al. (1975) examinaron 53 dientes y evaluaron el exudado inflamatorio por medio del método de electroforesis para el diagnóstico de dichas lesiones. Diecinueve de estos casos fueron denominados quistes. Posteriormente todos los casos fueron tratados endodónticamente y en el seguimiento (4 - 21 meses) hubo curación en 14 casos de quistes perirradiculares.

Otro de los estudios que encontró curación en grandes lesiones fue el de Çaliskan (2004) que evaluó 42 dientes anteriores con lesiones perirradiculares de gran tamaño ( 7 a $18 \mathrm{~mm}$ ), algunos casos presentaron exudado inflamatorio en el momento de realizar el tratamiento de conducto, este exudado fue evaluado bajo microscopio y se pudo identificar en algunas muestras cristales de colesterol, característico de los quistes perirradiculares. Todos los casos tuvieron un seguimiento de 2 a 10 años. Además, encontraron que en el $73,8 \%$ hubo curación completa de las lesiones.

En una serie de 10 casos con grandes lesiones parecidas a quistes también observaron curación en grandes lesiones. Todos los casos fueron tratados endodónticamente por vía ortógrada incluyendo patencia apical; sobrepreparación con limas de bajo calibre para obtener exudado inflamatorio; preparación químico-mecánica de sistema de conductos perirradiculares; medicación intraconducto con hidróxido de calcio con clorhexidina y, por último, fueron obturados con gutapercha y cemento sellador. En un periodo de 24 meses, observaron que 6 casos (60\%) 
habían curado, 3 casos (30 \%) estaban en proceso de curación sin presencia de signos y síntomas y el caso que no presentó curación fue sometido a cirugía perirradicular observando una biopelícula adherida a la superficie externa de la raíz, sugieren que por esta razón no hubo curación (Santos Soares et al., 2016).

Biopelículas adheridas a la superficie externa e interna del conducto radicular han sido observadas y relacionadas a lesiones periradiculares de gran tamaño, por lo general mayor a $10 \mathrm{~mm}$. Estas biopelículas son complejas, ya que se caracterizan por tener mayor número de especies y alta densidad de bacterias; indican que estas bacterias han tenido suficiente tiempo para establecer una biopelícula madura y organizada. Igualmente expresan que esto es de gran interés en la terapia endodóntica puesto que se han observado biopelículas tanto en el conducto principal como en istmos y ramificaciones difíciles de ser alcanzadas por los protocolos de desinfección implementados en la terapia endodóntica (Ricucci et al., 2010).

Por otra parte, Lin et al. (2007) explican que después de la terapia endodóntica convencional, el tejido epitelial que recubre el quiste deja de proliferar por la reducción de los mediadores inflamatorios, citosinas proinflamatorias y factores de crecimiento. Por otra parte, manifiestan, que las células epiteliales que se encuentran en la parte basal del tejido, se atrofian por medio de la apoptosis, esto viene dado por la falta de factores de supervivencia durante el proceso de cicatrización de los tejidos periradiculares.

Durante la cicatrización de las lesiones periradiculares la actividad osteoclástica disminuye por la reducción de citosinas que se encargan de la resorción del tejido óseo (Interleucina-1, Factor de necrosis tumoral, Interleucina-6) y la actividad osteoblástica comienza activar las proteínas morfogenéticas, factor transformante beta, factores similares a la insulina, factor de crecimiento derivado de las plaquetas, liberados por células estromales, osteoblastos, plaquetas con la finalidad de crear tejido óseo en la región perirradicular. Por otra parte, se puede formar una cicatriz apical, este tipo de curación o cicatrización, esta se ha caracterizado por presentar tejido cicatricial fibroso por la extensa destrucción del periostio, en estos casos por lo general están involucradas ambas corticales óseas (Lin et al., 2009).

Para finalizar es importante tener en cuenta que, aunque existan anatomías complejas como istmos y ramificaciones en el sistema de conductos radiculares, la terapia endodóntica en dientes con grandes lesiones ha demostrado ser eficaz, por lo tanto, esta debería ser la primera elección en el tratamiento de este tipo de casos, sin embargo, si hay persistencia de signos y síntomas después de realizar este tratamiento, sería adecuado realizar la cirugía perirradicular (Çaliskan; Santos Soares et al.).

\section{CONCLUSIONES}

Los quistes periradiculares han sido clasificados como quistes verdaderos o de bolsillo, por muchos años se mantuvo la teoría que los quistes eran autosustentables, es decir no dependían de microorganismos para mantenerse en el tejido perirradicular y el tratamiento de elección era la extracción o cirugía perirradicular. Sin embargo, varios estudios, utilizando métodos sensibles a la detección de microorganismos han determinado que el factor etiológico de ambos quistes es la presencia de microorganismos, en la parte interna y externa del conducto radicular y apoyan la realización de la terapia endodóntica convencional en dientes con grandes lesiones periradiculares asociadas a estos.

BRISSON, S. K.; BAASCH, A.; DE CASTRO BRASIL, S.; SAAVEDRA, F. J. D.; ARMADA, L. \& ALVES, F. R. F.¿Radicular cysts depend on endodontic infection? Int. J.Odontostomat., 15(3):626-633, 2021.

ABSTRACT: Radicular cysts, either the pocket or the true cysts, are originated by an inflammation. However, in the literature, there has been great controversy surrounding, firstly, the dependence of the infection contained within the radicular conducts and, secondly, the kind of endodontic treatment performed in this sort of injury. In order to clarify this controversy, the literature concerning radicular cysts will be reviewed and it will be explained what technique is the most appropriate for diagnosing true cysts and pocket cysts. Likewise, the theory of self-sustaining, as well as the endodontic treatment for large radicular injuries associated to such cysts, will be further explained. Nonetheless, nowadays it has been demonstrated that both cysts are associated to infections contained within the system of radicular conducts and that they are only morphologically different. In addition, the root canal treatment has been recommended for teeth with great injuries associated to cysts.

KEY WORDS: apical periodontitis, pocket apical cyst, true apical cyst. 


\section{REFERENCIAS BIBLIOGRÁFICAS}

Abbott, P. Classification, diagnosis and clinical manifestations of apical periodontitis. Endod. Topics., 8(1):36-54, 2004.

Alcantara, B. A.; Carli, M. L.; Beijo, L. A.; Pereira, A. A. \& Hanemann, J. A. Correlation between inflammatory infiltrate and epithelial lining in 214 cases of periapical cyst. Braz. Oral. Res., 27(6):49095, 2013.

Bernardi, L.; Visioli, F.; Nör, C. \& Rados, P. V. Radicular cyst: An update of the biological factors related to lining epithelium. $J$. Endod., 41(12):1951-61, 2015.

Bhaskar, S. Oral surgery--oral pathology conference No. 17, Walter Reed Army Medical Center. Periapical lesions--types, incidence, and clinical features. Oral. Surg. Oral. Med. Oral. Patho., 21(5):657-71, 1966.

Çaliskan, M. Prognosis of large cyst-like periapical lesions following nonsurgical root canal treatment: a clinical review. Int. Endod. J., 37(6):408-16, 2004.

Lalonde, E. R. \& Luebke, R. G. The frequency and distribution of periapical cysts and granulomas. Oral. Surg. Oral. Med. Oral. Patho., 25(6):861-8, 1968.

Lin, L. M.; Huang, G. T. \& Rosenberg, P. A. Proliferation of epithelial cell rests, formation of apical cysts, and regression of apical cysts after periapical wound healing. J. Endod., 33(8):908-16, 2007.

Lin, L. M.; Ricucci, D.; Lin, J. \& Rosenberg, P. Nonsurgical root canal therapy of large cyst-like inflammatory periapical lesions and inflammatory apical cysts. J. Endod., 35(5):607-15, 2009.

Morse, D. R.; Wolfson, E. \& Schacterle, G. R. Nonsurgical repair of electrophoretically diagnosed radicular cysts. J. Endon., 1(5):15863, 1975.

Nair, P. N.; Sjögren, U.; Krey, G.; Kahnberg, K. E. \& Sundqvist, G. Intraradicular bacteria and fungi in root-filled, asymptomatic human teeth with therapy resistant periapical lesions: a longterm light and electron microscopic follow-up study. J. Endod., 16(12):580-8, 1990.

Nair, P. N.; Sjögren, U.; Schumacher, E. \& Sundqvist, G. Radicular cyst affecting a root filled human tooth: A long-term post treatment follow-up. Int. Endo. J., 26(4):225.33, 1993.

Nair, P. N.; Pajarola, G.; Schroeder H. E. Types and incidence of human periapical lesion obtained with extracted teeth. Oral. Surg. Oral. Med. Oral. Patho., 81(1):93-102, 1996.

Nair, P. N. Apical periodontitis: a dynamic encounter between root canal infections. Periodontol. 2000, 13:121-48, 1997.

Nair, P. N. New perspectives on radicular cysts: do they heal? Int. Endo. J., 31(3):155-60, 1998.

Nair, P. N. Non-microbial etiology: periapical cysts sustain posttreatment apical periodontitis. Endod. Topics., 6(1):96-113, 2003.

Ricucci, D.; Pascon, E. A.; Ford, T. R. \& Langeland, K. Epithelium and bacteria in periapical lesions. Oral. Surg. Oral. Med. Oral. Patho. Oral. Radiol. Endod., 101(2):239-49, 2006.

Ricucci, D. \& Siqueira-jr, J. F. Biofilms and apical periodontitis: study of prevalence and association with clinical and histopathologic findings. J. Endod., 36(8):1277-88, 2010.

Ricucci, D.; Rõças, I. N.; Hernández, S. \& Siqueira-jr, J. F. "True" Versus "bay" apical Cyst: Clinical, radiographic, histopathologic and histobacteriologic features. J. Endo., 46(9):1217-27, 2020

Rosenberg, P. A.; Frisbie, J.; Lee, J.; Lee, K.; Frommer, H.; Kottal, S.; Phelan, J.; Lin, L. \& Fisch, G. Evaluation of pathologists (histopathology) and radiologists (Cone Beam Computed Tomography) differentiating radicular cysts from granulomas. J. Endod., 36(3):423-8, 2010.

Santos Soares, S. M.; Brito-Júnior, M.; de Souza, F. K.; Zastrow, E. V.; Cunha, C. O.; Silveira, F. F.; Nunes, E.; César, C. A.; Glória, J. C. \& Soares, J. A. Management of Cyst-like Periapical Lesions by Orthograde Decompression and Long-term Calcium Hydroxide/Chlorhexidine Intracanal Dressing: A Case Series. J. Endo., 42(7):1135-41, 2016.

Simon, J. Incidence of periapical cysts in relation to root canal. $J$. Endod., 6(11):845-8, 1980.

Siqueira-jr, J. F.; Rôças, I. N. Exploiting molecular methods to explore endodontic infections: Part 1-current molecular technologies for microbiological diagnosis. J. Endod., 31(6):411-23, 2005.

Siqueira-jr, J. F.; Rõças, I. N. Bacterial pathogenesis and mediators in apical periodontitis. Braz. Dent. J., 18(4):267-80, 2007.

Dirección para correspondencia

Karen Brisson Suárez

Avenida Venezuela del Rosal con Avenida Libertador

Torre Exa. Piso 6, Oficina 611

Caracas

VENEZUELA

E-mail: Brisson.karen@gmail.com 